\title{
On the Effect of Interest Rates Dynamics on Vietnamese Companies
}

\author{
Nguyen Khac Quoc Bao ${ }^{1} \&$ Dinh Thi Thu Hong ${ }^{1}$ \\ ${ }^{1}$ School of Finance, University of Economics Ho Chi Minh City, Vietnam \\ Correspondence: Nguyen Khac Quoc Bao, School of Finance, University of Economics Ho Chi Minh City, Ho \\ Chi Minh City, Vietnam. E-mail: nguyenbao@ueh.edu.vn
}

Received: March 5, 2015

Accepted: March 19, 2015

Online Published: April 25, 2015

doi:10.5539/ijef.v7n5p147

URL: http://dx.doi.org/10.5539/ijef.v7n5p147

\begin{abstract}
In this paper we set out a framework that will help Vietnamese companies to enhance their interest rate risk management practices. We start by analysing time series of Vietnamese Treasury bill rates. Using the maximum likelihood method we calibrate to these data seven models of interest rate dynamics: Vasicek (1977), Cox, Ingersoll and Ross (1985), Chan, Karolyi, Longstaff and Sanders (1992), Ahn and Gao (1999), Ait-Sahalia (1996), two factor version of Cox, Ingersoll and Ross (1985), and AR(1)-GARCH(1,1). Then using calibrated model parameters we calculate risk measures such as Value at Risk or Expected Shortfall and project the interest rates over three months. Finally we study the resulting risk measures as well as distributions of interest rates generated by each model and provide guidance regarding suitability of these models for risk management purposes.
\end{abstract}

Keywords: risk management, interest rates, maximum likelihood method

\section{Introduction}

Interest rates are one of the key financial variables in the economy. Changes in interest rates impact the way in which companies operate. First, changes in the interest rate affect companies' borrowing costs, which in turns impact their earnings. Second, changes in the interest rate impact the discounting of the future cash flows thereby affecting their present value. Third, interest rates determine the return on fixed income instruments, which are an important asset class for both individual and institutional investors.

There are different types of interest rates: spot rates, forward rates or swap rates. Among various types of interest rates, spot interest rate is the most important to us. This is because the main objective of this paper is to educate Vietnamese companies on managing interest rate risk. This involves measuring the exposure to adverse movements in the interest rate which presents a major business challenge for companies in Vietnam as future interest rates are uncertain. An interest rate model is a mathematical description of that uncertainty and we believe that when used correctly it can significantly enhance risk management capabilities of Vietnamese companies. Another reason why we suggest the use of interest rate models is due to the lack of liquidly traded derivatives on Vietnamese interest rate, which makes it particularly difficult for Vietnamese companies to hedge against unfavourable interest rate movements. We postulate that Vietnamese companies develop a set of robust risk management practices to quantify interest rate risk and subsequently incorporate them in the decision making process. The starting point is to analyse historical data and choose an appropriate interest rate model. Using the maximum likelihood method we calibrate seven such models to the time-series of Vietnamese Treasury bill rates and provide guidance regarding suitability of these models for risk management purposes. Next task involves quantifying interest rate risk which can be done by calculating Value at Risk, Expected Shortfall or scenario analysis using projected interest rate distributions. Examples of each of these are presented in this paper. Finally once the interest rate risk is quantified, this information needs to be applied in the company specific context to yield more informed business decisions.

The second objective of this paper is to use advanced financial models and data analysis to better understand the behaviour of the interest rates in Vietnam. This complements the main objective of this paper in that risk management heavily relies on thorough understanding of the behaviour of the underlying risk factors. Solid understanding of the behaviour of interest rates is important in developing realistic expectations about future interest rates movements. The remainder of this paper is organized as follows. In Section 2 we review related literature. In Section 3 we describe the data and methodology. Results are presented in Section 4. Finally, Section 


\section{5 concludes the paper.}

\section{Literature Review}

The last few decades have seen considerable research on interest rate modelling and the development of many different interest rate models. The first models of the instantaneous spot rate proposed in literature were time-homogeneous, meaning that dynamics of the instantaneous spot rate was driven by constant coefficients. One of such model is that of Vasicek (1977) where the instantaneous spot rate follows an Ornstein-Uhlenbeck process. In this model the distribution of the instantaneous spot rates is Gaussian which is creating the possibility of negative interest rates. Another early example is the model of Cox, Ingersoll and Ross (1985) who assumed that the instantaneous spot rate evolves as a square root process. As for this model, the conditional distribution of the instantaneous spot rates is non-central chi-square whereas the unconditional one is gamma. Another difference between these two models is that in the Cox, Ingersoll and Ross model volatility is proportional to the instantaneous spot rate, whereas in the Vasicek model it is constant. Both models have gained popularity mainly because their analytical tractability allowing to price bonds and bond options analytically. Both the Vasicek as well as the Cox, Ingersoll and Ross models are sometimes called equilibrium models because the bond pricing mechanism is derived under the market equilibrium condition.

Chan, Karolyi, Longstaff, and Sanders (1992) generalize these two models by assuming that the volatility is proportional to the power function of the instantaneous spot rate. Two factor version of the Cox, Ingersoll and Ross model has been described in Chen and Scott (2003). In this model instantaneous spot rate is assumed to be a sum of two factors, with each factor being driven by a square root process. Ahn and Gao (1999) discuss a model in which instantaneous spot rate follows an inverse of the square root process. The dynamics of the instantaneous spot rate in all these models reflects the requirement that interest rates should be mean-reverting.

Ait-Sahalia (1996) proposes a model of the instantaneous spot rate with nonlinear drift term. Hull and White (1990) extended the Vasicek model by introducing time-varying parameters in the model. Black and Karasinski (1991) develop a model where the instantaneous spot rate follows an exponential Ornstein-Uhlenbeck process with time-varying parameters. In their model volatility is proportional to the instantaneous spot rate and the distribution of the instantaneous spot rate is lognormal. The latter allows for explicit formulas for pricing caps and swaptions. Both the Hull and White as well as the Black and Karasinski models are examples of no-arbitrage models because they match the bond prices observed in the market and thus are preferred to value interest rate derivatives. Peterson, Stapleton and Subrahmanyam (1999) extend the Black and Karasinski model to multiple factors and apply it to pricing of American and Bermudan options on coupon bonds.

Brailsford and Maheswaran (1998) examine different models of the short-term interest rate in Australia, including the Chan, Karolyi, Longstaff, and Sanders model as well as the GARCH model. They find that time-varying volatility models outperform the Chan, Karolyi, Longstaff, and Sanders model. Buhler, Uhrig-Homburg, Walter and Weber (1999) test many interest rate models, including the two factor Cox, Ingersoll and Ross model, and find that models with two factors perform better compared to one factor models. Jagannathan, Kaplin and Sun (2003) examine the swaption pricing using the multifactor Cox, Ingersoll and Ross model and conclude that that increasing the number of factors does not improve the performance. Moraleda and Pelsser (2000) test three spot rate and two forward rate models and conclude that spot rate models outperform forward rate ones. Gupta and Subrahmanyam (2005) examine various interest rate models, including the Hull and White model, for pricing and hedging interest rate caps and floors. They conclude that two factor models improve pricing accuracy and hedging performance compared to one factor ones. Buetow, Hanke, and Fabozzi (2001) investigate an impact of various interest rate models, including the Black and Karasinski model, on the calculation of different interest rate risk metrics. They find that these models produce substantially different results and recommend using an interest rate model that best describes interest rate dynamics. Cairns (2004) also considers the consistency between the model dynamics and what is observed in the historical data as a highly desirable model feature.

\section{Data and Methodology}

We obtain monthly time-series of Vietnamese Treasury bill rates between January 1999 and August 2014 from the International Monetary Fund. Summary statistics are presented in Table 1.

Table 1. Summary statistics

\begin{tabular}{ccccccc}
\hline & Mean & Variance & Skewness & Kurtosis & Minimum & Maximum \\
\hline Treasury bill rate & 0.0605 & 0.0002 & 1.3895 & 5.9033 & 0.0334 & 0.1150 \\
\hline
\end{tabular}


The distribution of Vietnamese Treasury bill rates is skewed to the right and leptokurtic, that is peaked and fat tailed. Empirical evidence in Table 1 suggests that a non-constant volatility interest rate model will perform better than a constant volatility one.

We consider seven models of the interest rates dynamics that are described below. Since the objective of this paper is to provide guidance regarding a suitable interest rate model for risk management purposes, we restrict our analysis to fairly simple and tractable interest rate models. This is because a critical issue in selecting an interest rate model is its ease of application. For example, for some complex models it is difficult or almost impossible to provide efficient calibration or simulation algorithms. What is more, in a developing market such as Vietnam, complex models are particularly undesirable as complexity would prevent companies from using them.

In the Vasicek model the short rate dynamics is given by the following stochastic differential equation:

$$
d r_{t}=\kappa\left(\theta-v_{t}\right) d t+\sigma d W_{t}
$$

where $r_{t}$ is the short-term interest rate, $\theta$ is the long-term interest rate, $\kappa$ is the speed of mean-reversion of $r_{t}$ to its long-term mean $\theta, \sigma$ is the volatility of the instantaneous spot rate and $\mathrm{W}_{\mathrm{t}}$ is a standard Brownian motion.

The dynamics of the short rate in the Cox-Ingersoll-Ross model is given by:

$$
d r_{t}=\kappa\left(\theta-v_{t}\right) d t+\sigma \sqrt{r_{t}} d W_{t}
$$

where $r_{t}$ is the short-term interest rate, $\theta$ is the long-term interest rate, $\kappa$ is the speed of mean-reversion of $r_{t}$ to its long-term mean $\theta, \sigma$ is the volatility of the instantaneous spot rate and $\mathrm{W}_{\mathrm{t}}$ is a standard Brownian motion. We note that the Feller condition given by $2 \kappa \theta \geq \sigma^{2}$ ensures that $r_{t}$ is strictly positive.

In the Chan-Karolyi-Longstaff-Sanders model short rate evolves according to the following stochastic differential equation:

$$
d r_{t}=\kappa\left(\theta-v_{t}\right) d t+\sigma r_{t}^{\gamma} d W_{t}
$$

It is also worth mentioning that the parameters of all these models have a meaningful economic interpretation. The instantaneous spot rate is pulled towards its long-term mean $\theta$ with force determined by the speed of mean-reversion $\kappa$, whereas the dispersion of the spot rate distribution is determined by $\sigma$.

In the Ahn-Gao model the short rate dynamics is modelled as an inverse of the square root process:

$$
d r_{t}=r_{t}\left(\kappa-\left(\sigma^{2}-\kappa \theta\right) r_{t}\right) d t+\sigma r_{t}^{3 / 2} d W_{t}
$$

We note that the nonlinear drift term in this model allows to better capture the mean-reversion effect of the interest rates.

Another model of the short rate with a nonlinear drift term, proposed by Ait-Sahalia (1996), is specified as follows:

$$
d r_{t}=\left(a_{-1} r_{t}^{-1}+a_{0}+a_{1} r_{t}+a_{2} r_{t}^{2}\right) d t+\sigma r_{t}^{3 / 2} d W_{t}
$$

Due to their flexibility nonlinear drift models are able to capture asymmetric mean-reverting features.

Next model is the two factor Cox, Ingersoll and Ross model where short rate is a linear combination of two factors:

$$
r_{t}=y_{1, t}+y_{2, t}
$$

The factors, denoted as $\mathrm{y}_{1}$ and $\mathrm{y}_{2}$, are assumed to be independent and driven by square root processes as that in equation (2) above.

As for the $\mathrm{AR}(1)-\mathrm{GARCH}(1,1)$ model, the interest rate is specified as:

$$
r_{t}=\alpha_{0}+\varphi_{1} r_{t-1}+\varepsilon_{t}
$$

where $\varepsilon_{\mathrm{t}}=\sigma_{\mathrm{t}} \mathrm{z}_{\mathrm{t}}$ with $\mathrm{z}_{\mathrm{t}}$ being an independent and identically distributed error term following a normal distribution. In the above equation $\varphi_{1}$ measures the degree of persistence in the interest rate. The variance equation in this model has the following form:

$$
\sigma_{t}^{2}=\kappa+\alpha_{1} \varepsilon_{t-1}^{2}+\alpha_{2} \sigma_{t-1}^{2}
$$

In the variance equation $\alpha_{1}$ measures the extent to which a volatility shock feeds from one period to another, while $\alpha_{1}+\alpha_{2}$ measures at which rate this shock disappears over time. 


\section{Results}

The calibrated model parameters are displayed in Table 2. We note that these parameter estimates are based on 128 monthly observations. This is because the final 4 months will be used to backtest each model so that we can assess their out-of-sample performance.

Table 2. Calibrated model parameters

\begin{tabular}{cccccccccc}
\hline Model & $\kappa$ & $\theta$ & $\sigma$ & $\gamma$ & $\varphi_{1}$ & $\alpha_{-1}$ & $\alpha_{0}$ & $\alpha_{1}$ & $\alpha_{2}$ \\
\hline Vasicek & 1.4237 & 0.0564 & 0.0055 & & & & & & \\
CIR & 1.2712 & 0.0559 & 0.0221 & & & & & & \\
CKLS & 1.2078 & 0.0558 & 0.0346 & 0.6597 & & & & & \\
AG & 1.0181 & -16.861 & 0.3868 & & & & & & \\
Ait-Sahalia & & & & & & -0.0202 & 1.0939 & -117.277 & 76.609 \\
2FCIR & 1.5281 & 0.0002 & 0.3653 & & & & & & \\
& 0.0423 & 0.1147 & 0.0585 & & & & & & \\
AR(1)-GARCH(1,1) & 0.0000 & & & & 0.8814 & & 0.0067 & 0.2972 & 0.0000 \\
\hline
\end{tabular}

Based on the AR(1)-GARCH(1,1) model, $\varphi_{1}$ is positive which indicates that the interest rate at time $t$ is positively correlated with interest rate at time t-1. We note that $\beta_{1}$ is 0 , so that the GARCH process reduces to an $\mathrm{ARCH}$ process. We also note that while the mean-reversion rates and long-term interest rates are very similar for the Vasicek, the Cox, Ingersoll and Ross as well as the Chan, Karolyi, Longstaff and Sanders models, the latter model has much higher volatility of the instantaneous spot rate. As for the two factor Cox, Ingersoll and Ross model, one square root process is faster mean-reverting, has lower long-term interest rate and higher volatility of the instantaneous spot rate compared to the other square root process.

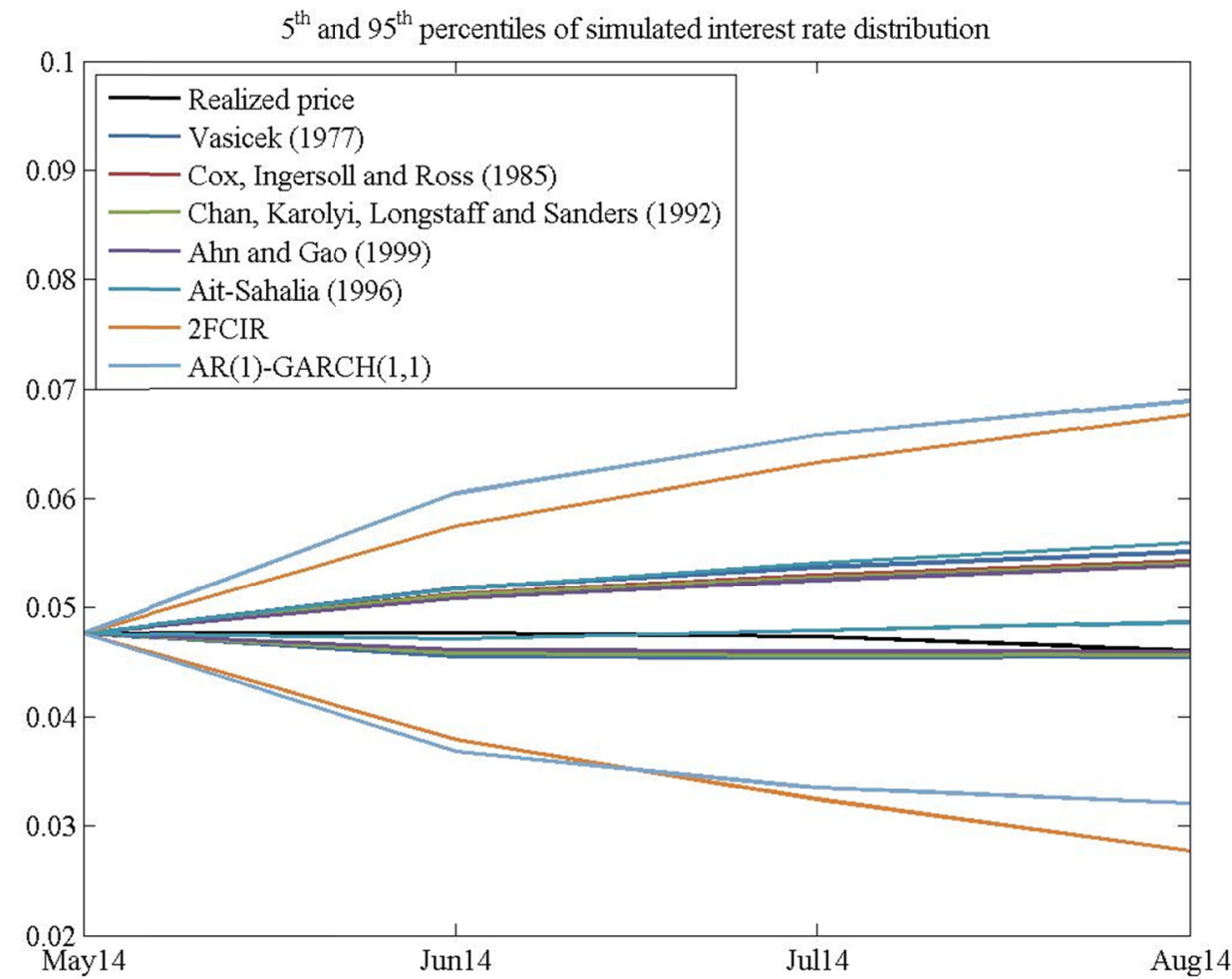

Figure 1. Realized interest rates as well as the 5th and 95th percentiles of simulated interest rate distributions

In order to compare the model fits we use the Akaike information criterion because it discourages overfitting by penalizing models with more parameters. Based on the lowest Akaike information criterion, the best model fit is achieved by the two factor Cox, Ingersoll and Ross model, followed by AR(1)-GARCH(1,1), Cox, Ingersoll and 
Ross, Chan, Karolyi, Longstaff and Sanders, Vasicek, Ahn and Gao and Ait-Sahalia models.

As mentioned earlier, we use model parameters in Table 2 to project the interest rate at May 2014 three months forward. Such projections provide valuable information about the likelihood of rising and falling interest rate scenarios occurring. Moreover, we compare interest rate distributions generated by each model with the realized interest rate over the final three months of the sample period to assess the out-of-sample performance of each model. As a minimum, interest rate model that would be suitable for interest rate risk management purposes must predict realized interest rates. In Figure 1 we display the realized interest rates as well as the 5th and 95th percentiles of simulated distributions. We note that these are obtained using 100,000 Monte Carlo simulations.

Figure 1 shows that the realized interest rates lie between the 5th and 95th percentiles of most simulated interest rate distributions. As hypothesized earlier, the two factor Cox, Ingersoll and Ross and the AR(1)-GARCH(1,1) models generate more realistic distributions of the interest rate compared to other models. This is because other models do not generate enough dispersion in the interest rate distribution. This is particularly pronounced for the Ait-Sahalia model because at July 2014 the realized interest rate falls below the 5 th percentile of the simulated distribution. We also note that both nonlinear drift models are the worst performing ones.

One important aspect of interest rate risk management is calculation of Value at Risk (VaR) or Expected Shortfall (ES). Given the distribution of the interest rates at time $T$, where $T>t=0, \mathrm{VaR}$ is calculated as the percentile of the loss distribution, where loss is defined as the difference between interest rate at time 0 and interest rate at time $\mathrm{T}$. VaR measures what will be the loss over the holding period that can happen some small probability equal to the percentile of the loss distribution. In other words, there is only this small probability that the actual loss will exceed VAR. ES on the other hand measures the average loss over the holding period given that the loss is greater than VaR. VaR and ES estimates for each model are shown in Table 3.

Table 3. VaR and ES

\begin{tabular}{cccccccc}
\hline Risk measure & Vasicek & CIR & CKLS & AG & Ait-Sahalia & 2FCIR & AR(1)-GARCH(1,1) \\
\hline VaR & $0.1212 \%$ & $0.1152 \%$ & $0.1187 \%$ & $0.0939 \%$ & $0.0183 \%$ & $4.1738 \%$ & $1.1155 \%$ \\
ES & $0.2178 \%$ & $0.1978 \%$ & $0.1981 \%$ & $0.1641 \%$ & $0.0629 \%$ & $4.5161 \%$ & $1.5964 \%$ \\
\hline
\end{tabular}

We conclude that both VaR and ES are very similar for the the Vasicek, the Cox, Ingersoll and Ross as well as the Chan, Karolyi, Longstaff and Sanders models. As for two factor Cox, Ingersoll and Ross and AR(1)-GARCH(1,1) models, they produce much higher figures while the Ait-Sahalia model produces much lower figures. This highlights another important aspect of interest rate risk management, that is the model risk. It can be defined as the possibility of suffering financial losses due to misspecification of the risk-management model. Model risk has become an important concept in financial valuation as well as risk management. It has been extensively studied in the literature and various authors caution that model users should not underestimate the limitations of their models. Given the results presented in Table 3, we believe that it is the two factor Cox, Ingersoll and Ross model that provides more realistic assessment of interest rate risk. This is motivated by the fact that this model fits better to historical data as well as is able to better capture time-varying volatility of interest rates.

Another approach to manage interest rate risk is to use the simulated interest rates to the project the values of assets or liabilities that are sensitive to interest rates. This is particularly relevant for financial institutions because their balance sheets are particularly sensitive to interest rate fluctuations. The main factor motivating regulators' strong interest in measuring and assessing the interest rate risk in the financial sector is that regulators want to determine whether financial institutions have enough capital to cover interest rate risk arising from their business activities and strategies.

\section{Conclusion}

In this paper we focus on managing the interest rate risk. We demonstrate how interest rate models can be used to enhance risk management capabilities of Vietnamese companies. Using time series of Vietnamese Treasury bill rates we calibrate seven interest rate models: Vasicek (1977), Cox, Ingersoll and Ross (1985), Chan, Karolyi, Longstaff and Sanders (1992), Ahn and Gao (1999), Ait-Sahalia (1996), two factor version of Cox, Ingersoll and Ross (1985), and AR(1)-GARCH(1,1). Finally, we use calibrated model parameters to calculate Value at Risk and Expected Shortfall as well as project the interest rates over three months. Our results suggest that the two factor Cox, Ingersoll and Ross model outperforms other models. Our results also suggest that there is no support for the nonlinear drift models as both the Ahn and Gao as well as the Ait-Sahalia models are the worst 
performing models. We conclude that the two factor Cox, Ingersoll and Ross model is the most suitable for risk management purposes. This is motivated by its superior fit to historical data as well as the out-of-sample performance.

\section{Acknowledgements}

This research was funded by a grant from University of Economics Ho Chi Minh City.

\section{References}

Ahn, D. H., \& Gao, B. (1999). A parametric nonlinear model of term structure dynamics. Review of Financial Studies, 12(4), 721-762. http://dx.doi.org/10.1093/rfs/12.4.721

Ait-Sahalia, Y. (1996). Nonparametric pricing of interest rate derivative securities. Econometrica, 64(3), 527-560. http://dx.doi.org/10.2307/2171860

Black, F., \& Karasinski, P. (1991). Bond and option pricing when short rates are lognormal. Financial Analysts Journal, 47(4), 52-59. http://dx.doi.org/10.2469/faj.v47.n4.52

Brailsford, T. J., \& Maheswaran, K. (1998). The dynamics of the australian short-term interest rate. Australian Journal of Management, 23(2), 213-234. http://dx.doi.org/10.1177/031289629802300206

Buetow, G. W., Hanke, B., \& Fabozzi, F. J. (2001). Impact of different interest rate models on bond value measures. Journal of Fixed Income, 11(3), 41-53. http://dx.doi.org/10.3905/jfi.2001.319304

Bühler, W., Uhrig-Homburg, M., Walter, U., \& Weber, T. (1999). An empirical comparison of forward-rate and spot-rate models for valuing interest-rate options. Journal of Finance, 54(1), 269-305. http://dx.doi.org/10.1111/0022-1082.00104

Chan, K. C., Karolyi, G. A., Longstaff, F. A., \& Sanders, A. B. (1992). An empirical comparison of alternative models of the short-term interest rate. Journal of Finance, 47(3), 1209-1227. http://dx.doi.org/10.2307/2328983

Chen, R. R., \& Scott, L. (2003). Multi-factor cox-ingersoll-ross models of the term structure: Estimates and tests from a kalman filter model. Journal of Real Estate Finance and Economics, 27(2), 143-172. http://dx.doi.org/10.1023/A\%3A1024736903090

Cox, J. C., Ingersoll, J. E., \& Ross, S. A. (1985). A theory of the term structure of interest rates. Econometrica, 53(2), 385-407. http://dx.doi.org/10.2307/1911242

Cairns, A. J. G. (2004). A family of term-structure models for long-term risk management and derivative pricing. Mathematical Finance, 14(3), 415-444. http://dx.doi.org/10.1111/j.0960-1627.2004.00198.x

Gupta, A., \& Subrahmanyam, M. G. (2005). Pricing and hedging interest rate options: Evidence from cap-floor markets. Journal of Banking \& Finance, 29(3), 701-733. http://dx.doi.org/10.1016/j.jbankfin.2004.05.025

Hull, J., \& White, A. (1990). Pricing interest rate derivative securities. The Review of Financial Studies, 3(4), 573-592. http://dx.doi.org/10.1093/rfs/3.4.573

Jagannathan, R., Kaplin, A., \& Sun, S. G. (2003). An evaluation of multi-factor cir models using libor, swap rates, and cap and swaption prices. Journal of Econometrics, 116(1-2), 113-146. http://dx.doi.org/10.1016/S0304-4076(03)00105-2

Moraleda, J. M., \& Pelsser, A. (2000). Forward versus spot interest rate models of the term structure: An empirical comparison. Journal of Derivatives, 7(3), 9-21. http://dx.doi.org/10.3905/jod.2000.319122

Peterson, S., Stapleton, R. C., \& Subrahmanyam, M. G. (1999). A two factor lognormal model of the term structure and the valuation of american-style options on bonds. Working paper, New York University.

Vasicek, O. (1977). An equilibrium characterization of the term structure. Journal of Financial Economics, 5(2), 177-188. http://dx.doi.org/10.1016/0304-405X(77)90016-2

\section{Copyrights}

Copyright for this article is retained by the author(s), with first publication rights granted to the journal.

This is an open-access article distributed under the terms and conditions of the Creative Commons Attribution license (http://creativecommons.org/licenses/by/3.0/). 